\title{
Medication burden and inappropriate prescription risk among elderly with advanced chronic kidney disease
}

\author{
Clarisse Roux-Marson ${ }^{1,2^{*}}$, Jean Baptiste Baranski ${ }^{1}$, Coraline Fafin ${ }^{3}$, Guillaume Exterman ${ }^{4}$, Cecile Vigneau ${ }^{5,6}$, \\ Cecile Couchoud ${ }^{7,8}$, Olivier Moranne $2,3^{*}$ and P. S. P. A. Investigators
}

\begin{abstract}
Background: Elderly patients with chronic kidney disease (CKD) frequently present comorbidities that put them at risk of polypharmacy and medication-related problems. This study aims to describe the overall medication profile of patients aged $\geq 75$ years with advanced CKD from a multicenter French study and specifically the renally (RIMs) and potentially inappropriate-for-the-elderly medications (PIMs) that they take.

Methods: This is a cross-sectional analysis of medication profiles of individuals aged $\geq 75$ years with eGFR $<20 \mathrm{ml} / \mathrm{min} / 1.73 \mathrm{~m} 2$ followed by a nephrologist, who collected their active prescriptions at the study inclusion visit. Medication profiles were first analyzed according to route of administration, therapeutic classification. Second, patients were classified according to their risk of potential medication-related problems, based on whether the prescription was a RIM or a PIM. RIMs and PIMs have been defined according to renal appropriateness guidelines and to Beer's criteria in the elderly. RIMs were subclassified by 4 types of category: (a) contraindication; (b) dose modification is recommended based on creatinine clearance $(\mathrm{CrCl})$; (c) dose modification based on $\mathrm{CrCl}$ is not recommended but a maximum daily dose is mentioned, (d) no specific recommendations based on $\mathrm{CrCl}$ : "use with caution", "avoid in severe impairment", "careful monitoring of dose is required" "reduce the dose".

Results: We collected 5196 individual medication prescriptions for 556 patients, for a median of 9 daily medications [7-11]. Antihypertensive agents, antithrombotics, and antianemics were the classes most frequently prescribed. Moreover, $77.0 \%$ of patients had at least 1 medication classified as a RIM. They accounted $31.3 \%$ of the drugs prescribed and $9.25 \%$ was contraindicated drugs. At least 1 PIM was taken by 57.6 and $45.5 \%$ of patients had at least one medication classified as RIM and PIM. The prescriptions most frequently requiring reassessment due to potential adverse effects were for proton pump inhibitors and allopurinol. The PIMs for which deprescription is especially important in this population are rilmenidine, long-term benzodiazepines, and anticholinergic drugs such as hydroxyzine.

(Continued on next page)
\end{abstract}

\footnotetext{
*Correspondence: clarisse.roux@chu-nimes.fr; olivier.moranne@chu-nimes.fr

'Department of Pharmacy, Nîmes University Hospital, Nîmes, France

¿2aboratoire Epidemiologie, Santé Publique, Biostatistiques, Université Montpellier, EA2415 Nimes, France

Full list of author information is available at the end of the article
}

(c) The Author(s). 2020 Open Access This article is licensed under a Creative Commons Attribution 4.0 International License, which permits use, sharing, adaptation, distribution and reproduction in any medium or format, as long as you give appropriate credit to the original author(s) and the source, provide a link to the Creative Commons licence, and indicate if changes were made. The images or other third party material in this article are included in the article's Creative Commons licence, unless indicated otherwise in a credit line to the material. If material is not included in the article's Creative Commons licence and your intended use is not permitted by statutory regulation or exceeds the permitted use, you will need to obtain permission directly from the copyright holder. To view a copy of this licence, visit http://creativecommons.org/licenses/by/4.0/. The Creative Commons Public Domain Dedication waiver (http://creativecommons.org/publicdomain/zero/1.0/) applies to the data made available in this article, unless otherwise stated in a credit line to the data. 
(Continued from previous page)

Conclusion: We showed potential drug-related problems in elderly patients with advanced CKD. Healthcare providers must reassess each medication prescribed for this population, particularly the specific medications identified here.

Trial registration: NCT02910908.

Keywords: Chronic kidney disease, Elderly, Medication prescription, Polypharmacy

\section{Background}

The increasing prevalence of chronic kidney disease (CKD) particularly affects older and aging populations [1]. The elderly frequently present multiple comorbidities that lead to polypharmacy and render them vulnerable to medication-related problems, including adverse drug reactions (ADRs) [2]. Elderly patients with CKD require many prescription medications to slow the progression of their renal disease, control specific complications, and manage frequent comorbidities [2]. Because both the aging process and kidney disease modify the pharmacokinetic and pharmacodynamic profiles of drugs, the overall incidence of ADRs is 3 to 10 times higher in older adults with CKD than in those without it [3]. Non-adherence to medication, often reported in patients with CKD as in those with other chronic medical conditions, results in lessened therapeutic response, highly variable dosing, and toxicity [4]. Moreover previous studies have reported that $15-67 \%$ of prescriptions for patients with impaired renal function contain errors such as inappropriate doses or intervals, contraindications, or precautions related to renally inappropriate medications (RIMs) [5, 6]. In France, Laroche et al. developed a list adapting the North American Beers' criteria that are widely used to identify potentially inappropriate-for-the-elderly medications (PIMs) [7]. PIMs are defined as medications that should be generally avoided in people aged $\geq 75$ years because they are either ineffective or at risk of medication-related problems and have a safer alternative [8].

Using this list, Laroche et al. showed that the prevalence of PIMs in older patients admitted to a French acute geriatric unit was 66\% [9]. Jones et al. reported a PIM rate of $13 \%$ among 100 patients in the USA $\geq 70$ years with CKD stages 3-5 [10]. Not surprisingly, some studies suggested that inappropriate medication is related to healthcare costs and utilization of healthcare services such as hospitalization, in- and outpatient visits, and emergency department admissions [11]. Most of these studies are from the United States of America and describe various medication-related issues or inappropriate medications in patients with stage 3-4 CKD or on dialysis $[2,6]$. Few studies had previously described prescription patterns and inappropriate medication in nondialysis elderly patients with advanced CKD $[1,12]$. No study focused only on non-dialysis elderly patients with eGFR $<20 \mathrm{ml} / \mathrm{min} / 1.73$.

The aim of our study is to describe, first, the overall medication profile of patients $\geq 75$ years with advanced CKD (eGFR $<20 \mathrm{ml} / \mathrm{min} / 1.73 \mathrm{~m} 2)$ from the multicenter French PSPA study (Parcours de Soin Personnes Agées in French, that is, Care Pathway of the Elderly), and second, which RIMs and PIMs are used most.

\section{Methods \\ Population and data collection}

The PSPA multicenter prospective study set up a cohort of patients $\geq 75$ years with advanced CKD.

Patients recruited by nephrologists at 24 nephrology centers throughout France (listed in the appendix as collaborators) met the following inclusion criteria: older than 75 years, CKD with eGFR $<20 \mathrm{ml} / \mathrm{min} / 1.73 \mathrm{~m} 2$ (estimated by the sMDRD formula), without a prior kidney transplant, and at least one nephrology clinic visit before enrollment. Consecutive inclusion of in- and outpatients took place over 4 months in each center, with all patients included within 1 year (2009-2010) [13].

Exclusion criteria were acute renal failure and late referral, defined by dialysis starting without previous nephrologist follow-up. The inclusion questionnaire asked for demographic data, clinical conditions (primary renal disease, comorbidities and disabilities), mobility (ability to walk with or without help), living independently in the community or not, and laboratory data. The Institutional Review Board and Ethics Committee of the research institution (Nîmes University Hospital Center), as well as two national bodies, the National Data Protection Authority (CNIL) and the Consultative Committee on the Treatment of Information on Personal Health Data for Research Purposes (CCTIRS), approved the study, which was registered as clinical trial number NCT02910908.

A nephrologist collected active prescriptions at the inclusion visit from the patients. Over-the-counter medications, pro re nata, and self-medication were not collected. The specific information collected for each drug included: drug, brand name, route of administration (transdermal, intravenous, subcutaneous, oral, inhalation, suppository, or eye drops) and dosage. Drugs were coded according to the WHO (World Health 
Organization) Anatomical Therapeutic Chemical (ATC) classification system [14].

\section{Method}

We performed a cross-sectional analysis of the medication profiles of the patients included in the PSPA study. First, the medication prescriptions were described for the total population according to ATC classification, and the patient's characteristics according to the tertile of number of daily medications taken. We focused especially on the use of renin angiotensin system inhibitors (RASi), defined as either angiotensin receptor blockers (ARBs) or angiotensin-converting enzyme inhibitors (ACEi) according to specific comorbidities, such as diabetes, heart failure, and nephropathy.

Second, patients were classified according to their risk of potential medication-related problems, based on whether the prescription was a RIM or a PIM. The RIM group comprises medications with any of renal contraindications, dose adjustments, or precautions/warnings according to the patient's eGFR, as listed in the French Vidal drug dictionary [14] as well as the database on the GPRwebsite, an online pharmacy reference guide, that updates renal dose adjustment guidelines based on international pharmacokinetic studies [15]. According to these guidelines, RIMs are subclassified by 4 types of category: (a) contraindication; (b) dose modification is recommended based on creatinine clearance $(\mathrm{CrCl}) ;(\mathrm{c})$ dose modification based on $\mathrm{CrCl}$ is not recommended but a maximum daily dose is mentioned, (d) no specific recommendations based on $\mathrm{CrCl}$ : "use with caution", "avoid in severe impairment", "careful monitoring of dose is required" "reduce the dose".

The PSPA cohort included patients with advanced CKD according to their GFR estimated by the MDRD (Modification of Renal Diet Disease) formula. For drug dosing, KDIGO (Kidney Disease: Improving Global Outcomes), the FDA (Food and Drug Administration), and the EMA (European Medicines Agency) all recommend using an estimated GFR value not adjusted for the body surface area (BSA) [16, 17]. As in pharmacology, the Cockroft-Gault (CG) equation is still recommended to adapt drug dosage; we thus defined RIMs according to the CG equation in $\mathrm{ml} / \mathrm{min}$. Moreover, the MDRD formula estimate the mGFR with standardized BSA in $\mathrm{mL} /$ min/1.73 m2 while CG formula estimate the creatinine clairance in $\mathrm{mL} / \mathrm{min}$ without BSA standardization. The PIM group includes medications potentially inappropriate for elderly patients according to Laroche criteria adapting the North American Beers' criteria [18]. Finally, we described the RIM and PIM medications most frequently prescribed and the patient characteristics associated with their prescription.

\section{Statistical analysis}

Patient characteristics and medications are described for the total population. Normally distributed variables are expressed as means $( \pm \mathrm{SD})$ and non-normally distributed variables as medians and their interquartile ranges.

Patient characteristics associated with at least one PIM prescriptions, and RIM prescriptions, respectively, were evaluated by univariate and multivariate analysis using standard or polytomous logistic regression analysis.

The variables with $p$-values $<0.20$ in the univariate analysis were selected for multivariate analysis. All pvalues were two-tailed with $<0.05$ defined as statistically significant. Analyses were performed with SAS, version 9.3 (SAS Institute, www.sas.com).

\section{Results}

\section{Study population}

Between 2009 and 2010, 573 patients were included in the PSPA study, and baseline medication prescriptions were available for 556 [13]. Mean age at inclusion was 82 years, $57 \%$ were men, and median eGFR was 14.2 [11.0-16.7] $\mathrm{ml} / \mathrm{min} / 1.73 \mathrm{~m} 2$ with MDRD and 13 [10.115.4] $\mathrm{ml} / \mathrm{min}$ with the CG formula. These 556 patients together took 5196 separate medications, mainly orally (89.0\%). The median number of drugs per day per patient was 9 [7-11], split into 3 tertile groups: 6 [2-7]; 9 [8-10]; and 12 [11-24]. The characteristics of the overall population according to tertile of daily drugs are presented in the Table 1 . The tertile 1, 2 and 3 are respectively composed of 155 patients (28\%), 210 patients (38\%), and 191 patients (34\%). Diabetes, overweight, higher proteinuria, and nephropathy were associated with the prescriptions of more oral drugs to take each day in the univariate analysis; after adjustment in the multivariate analysis, only diabetes was associated with more daily oral medications (Table 1 ).

\section{Patterns of medication use and frequency}

The 3 most common ATC medication classes were those for the cardiovascular system, alimentary tract and metabolism, and the blood (ATC Classes C, A, and B, respectively) (Table 2). In total, $98.0 \%$ of patients had at least 1 cardiovascular system medication prescribed, followed by drugs for alimentary tract and metabolism, with $82.6 \%$ of patients taking at least 1 medication of this class, and $72.3 \%$ of patients taking at least 1 blood medication.

Antihypertensive treatments were common, with $97.0 \%$ of patients prescribed at least 1 medication of this type. Diuretics were widely prescribed, with $74.3 \%$ of patients taking at least 1 medication. At least 1 RASi (i.e., $\mathrm{ARB}$ or $\mathrm{ACEi}$ ) was prescribed for $47.1 \%$ of patients in this overall population of elderly people with advanced CKD, for $53 \%$ of the patients with diabetes, $40 \%$ of those with chronic heart failure (CHF), and $40 \%$ of those with 
Table 1 Characteristics of the population, overall and acGElcording to the number of medications taken daily

\begin{tabular}{|c|c|c|c|c|}
\hline & \multirow{2}{*}{$\begin{array}{l}\text { Overall } \\
\text { population }\end{array}$} & \multicolumn{3}{|c|}{ Tertile groups of number of drug prescriptions daily } \\
\hline & & Tertile 1 & Tertile 2 & Tertile 3 \\
\hline Number of patients & 556 patients & $155(28 \%)$ & $210(38 \%)$ & $191(34 \%)$ \\
\hline Number of daily drug prescriptions: $\mathrm{n}[\mathrm{IQR}]$, (range) & & $6.0[5.0 ; 7.0],(2-7)$ & $9.0[8.0 ; 10.0],(8-10)$ & $12.0[11.0 ; 13.0],(11-24)$ \\
\hline \multicolumn{5}{|l|}{ Patients' characteristics } \\
\hline Age (year): Mean $\pm S D$ & $82.5 \pm 4.8$ & $82.6 \pm 5.0$ & $82.6 \pm 4.6$ & $82.2 \pm 4.9$ \\
\hline Male & $318(57 \%)$ & $94(61 \%)$ & $115(55 \%)$ & $109(57 \%)$ \\
\hline \multicolumn{5}{|l|}{ Blood pressure (mmHg) } \\
\hline SBP Median [IQ] & $142.0[130.0 ; 160.0]$ & $140.0[130.0 ; 160.0]$ & $142.0[130.0 ; 159.0]$ & $143.5[130.0 ; 160.0]$ \\
\hline DBP Median [IQ] & $73.5[69.0 ; 80.0]$ & $73.0[69.0 ; 80.0]$ & $75.0[70.0 ; 80.0]$ & $72.0[68.0 ; 80.0]$ \\
\hline Body mass index (BMI): (kg/m2) & $26.5 \pm 5.0$ & $25.7 \pm 4.8$ & $26.3 \pm 4.9$ & $27.3 \pm 5.1^{\mathrm{a}}$ \\
\hline Diabetes & $219(39 \%)$ & $53(34 \%)$ & $68(32 \%)$ & $98(51 \%)^{b}$ \\
\hline Chronic heart failure & $194(35 \%)$ & $52(34 \%)$ & $65(31 \%)$ & $77(40 \%)$ \\
\hline Chronic respiratory disease & $62(11 \%)$ & $16(10 \%)$ & $17(8 \%)$ & $29(15 \%)$ \\
\hline Peripheral vascular disease & $138(25 \%)$ & $39(25 \%)$ & $48(23 \%)$ & $51(27 \%)$ \\
\hline Cerebrovascular disease & $75(13 \%)$ & $22(14 \%)$ & $25(12 \%)$ & $28(15 \%)$ \\
\hline Dysrhythmia & $155(28 \%)$ & $35(23 \%)$ & $61(29 \%)$ & $59(31 \%)$ \\
\hline Active malignancy & $55(10 \%)$ & $16(10 \%)$ & $20(10 \%)$ & $19(10 \%)$ \\
\hline Behavioral disorders & $53(10 \%)$ & $19(12 \%)$ & 19 (9\%) & $15(8 \%)$ \\
\hline Residence: independently at home & $508(91 \%)$ & $141(91 \%)$ & 195 (93\%) & $172(90 \%)$ \\
\hline Mobility: walks unassisted & $499(90 \%)$ & $136(88 \%)$ & 190 (90\%) & $173(91 \%)$ \\
\hline Hemoglobin $(\mathrm{g} / \mathrm{dl})$ median $[\mathrm{IQ}]$ & $11.4[10.4 ; 12.4]$ & $11.3[10.2 ; 12.4]$ & $11.5[10.5 ; 12.3]$ & $11.3[10.4 ; 12.4]$ \\
\hline eGFR (CG) (ml/min) Median [IQ] & $13.0[10.1 ; 15.4]$ & $25.0[16.8 ; 30.9]$ & $23.9[19.0 ; 30.4]$ & $25.2[18.4 ; 30.1]$ \\
\hline eGFR (MDRD) (ml/min/1.73 m2) Median [IQ] & $14.2[11.1 ; 16.7]$ & $14.3[10.9 ; 16.7]$ & $14.4[11.3 ; 17.1]$ & $13.8[10.9 ; 16.5]$ \\
\hline \multicolumn{5}{|l|}{ Proteinuria (g/g): n(\%) } \\
\hline$<0.5$ & $174(31 \%)$ & $45(29 \%)$ & $78(37 \%)$ & $51(27 \%)$ \\
\hline$[0.5-1$ & $105(19 \%)$ & $40(26 \%)$ & $40(19 \%)$ & $25(13 \%)$ \\
\hline$\geq 1$ & $212(38 \%)$ & $57(37 \%)$ & 70 (33\%) & $85(45 \%)$ \\
\hline Miss & $65(12 \%)$ & $13(8 \%)$ & $22(10 \%)$ & $30(16 \%)^{a}$ \\
\hline \multicolumn{5}{|l|}{ Nephropathy } \\
\hline Vascular & $204(37 \%)$ & $49(32 \%)$ & $93(44 \%)$ & $62(32 \%)^{a}$ \\
\hline Diabetic & $135(24 \%)$ & $31(20 \%)$ & $37(18 \%)$ & $67(35 \%)$ \\
\hline Undetermined & $99(18 \%)$ & $32(21 \%)$ & $37(18 \%)$ & $30(16 \%)$ \\
\hline Glomerulopathy & $57(10 \%)$ & $17(11 \%)$ & $25(12 \%)$ & $15(8 \%)$ \\
\hline Tubulointerstitial & $61(11 \%)$ & $26(17 \%)$ & $18(9 \%)$ & $17(9 \%)$ \\
\hline
\end{tabular}

a: Tertile1 vs Tertile3, $p$-value $<0.05$ in univariate analysis

$b^{b}$ : Tertile1 vs Tertile3, $p$-value $<0.05$ in multivariate analysis

neither diabetes nor CHF (See additional file 1). Drugs for acid-related disorders such as proton pump inhibitors (PPIs) were prescribed to $39.2 \%$ of patients. Medications for subcutaneous administration accounted for 390 prescriptions (7.5\% of the entire population) for $313 \mathrm{pa}-$ tients (56.3\%), including erythropoietin and insulin (64.0 and $30.0 \%$ of subcutaneous medication prescriptions, respectively).

At least 1 RIM was prescribed to $77.0 \%$ of all patients; they accounted $31.3 \%$ of the drugs prescribed (Fig. 1): (a) At least 1 medication that is contraindicated was prescribed to $10.8 \%$ of all patients $(9.25 \%$ of drugs prescribed) (Fig. 1). Among the contraindicated medications, those most frequently prescribed were rilmenidine (16.5\% of patients), rosuvastatin $(6.5 \%)$, alfuzosin (5.8\%), and buflomedil (3.6\%) (Table 3).

(b) At least 1 medication whose the dose modification is recommended based on $\mathrm{ClCr}$ was prescribed to $66.2 \%$ of all patients (10.2\% of drugs prescribed); Allopurinol (30.0\% of patients), atenolol (6.1\% of 
Table 2 Most common medication classes according to the WHO Anatomical Therapeutic Chemical (ATC) classification system

\begin{tabular}{|c|c|c|c|}
\hline \multicolumn{2}{|l|}{ ATC } & $\begin{array}{l}\text { Number of medication } \\
\text { prescriptions: } \mathrm{n}(\%)\end{array}$ & $\begin{array}{l}\text { Number of patients with at least } 1 \text { prescription of } \\
\text { this type: } \mathrm{n}(\%)\end{array}$ \\
\hline \multicolumn{2}{|c|}{ Alimentary tract and metabolism (A) } & $934(18.0 \%)$ & $459(82.6 \%)$ \\
\hline $\mathrm{A} 11$ & Vitamins & $306(5.89 \%)$ & $245(44.1 \%)$ \\
\hline $\mathrm{A} 02$ & Drugs for acid-related disorders & $224(4.31 \%)$ & $218(39.2 \%)$ \\
\hline $\mathrm{A} 10$ & Drugs used in diabetes & $179(3.44 \%)$ & $135(24.3 \%)$ \\
\hline A06 & Drugs for constipation & $98(1.89 \%)$ & $83(14.9 \%)$ \\
\hline \multicolumn{2}{|c|}{$\begin{array}{l}\text { Alimentary tract and metabolism medications } \\
\text { Others }\end{array}$} & $127(2.44 \%)$ & $118(21.2 \%)$ \\
\hline \multicolumn{2}{|c|}{ Blood and blood-forming organs (B) } & $559(10.8 \%)$ & $402(72.3 \%)$ \\
\hline B01 & Antithrombotic agents & $395(7.60 \%)$ & $340(61.2 \%)$ \\
\hline B03 & Antianemic preparations & $164(3.20 \%)$ & $162(29.1 \%)$ \\
\hline \multicolumn{2}{|c|}{ Cardiovascular system (C) } & $2031(39.1 \%)$ & $545(98.0 \%)$ \\
\hline $\mathrm{CO3}$ & Diuretics & $431(8.29 \%)$ & $413(74.3 \%)$ \\
\hline C08 & Calcium channel blockers & $316(6.08 \%)$ & $310(55.7 \%)$ \\
\hline $\mathrm{C} 10$ & Lipid-modifying agents & $286(5.50 \%)$ & $276(49.6 \%)$ \\
\hline C09 & Agent acting on the renin-angiotensin system & $281(5.41 \%)$ & $262(47.1 \%)$ \\
\hline $\mathrm{CO}$ & Beta-blocking agents & $268(5.16 \%)$ & $264(47.5 \%)$ \\
\hline C02 & Antihypertensive drugs & $203(3.91 \%)$ & $166(29.9 \%)$ \\
\hline \multicolumn{2}{|c|}{$\begin{array}{l}\text { Antihypertensive medications } \\
\text { Others }\end{array}$} & $246(4.73 \%)$ & $196(35.3 \%)$ \\
\hline \multicolumn{4}{|c|}{ Musculoskeletal system (M) } \\
\hline M04 & Antigout preparations & $171(3.29 \%)$ & $167(30.03 \%)$ \\
\hline \multicolumn{2}{|c|}{$\begin{array}{l}\text { Musculoskeletal system medications } \\
\text { Others }\end{array}$} & $34(1 \%)$ & $165(29.7 \%)$ \\
\hline \multicolumn{2}{|c|}{ Nervous system (N) } & $450(8.70 \%)$ & $273(49.1 \%)$ \\
\hline N05 & Psycholeptics & $212(4.08 \%)$ & $184(33.1 \%)$ \\
\hline N06 & Psychoanaleptics & $95(1.83 \%)$ & $82(14.8 \%)$ \\
\hline N02 & Analgesics & $110(2.12 \%)$ & $94(16.9 \%)$ \\
\hline Other & nervous system medications & $33(0.64 \%)$ & $32(5.8 \%)$ \\
\hline \multicolumn{2}{|c|}{ Various ( $)$} & $397(7.6 \%)$ & $296(53.2 \%)$ \\
\hline \multirow[t]{2}{*}{ V03 } & \multirow{2}{*}{$\begin{array}{l}\text { Drugs for treatment of hyperkalemia and } \\
\text { hyperphosphatemia }\end{array}$} & $122(2.35 \%)$ & $122(21.94 \%)$ \\
\hline & & $275(5.29 \%)$ & $242(43.53 \%)$ \\
\hline \multicolumn{2}{|c|}{ Other class of medications } & $620(11.9 \%)$ & 401 (72.1\%) \\
\hline
\end{tabular}

patients), acebutolol (5.6\% of patients), lorazepam (5.6\% of patients) are the drugs the most often prescribed (Table 4).

(c) At least 1 medication whose the dose modification based on $\mathrm{CrCl}$ is not recommended but a maximum daily dose is mentioned was prescribed to $31.3 \%$ of all patients (3.65\% of drugs prescribed); Ramipril (12.6\% of patients), nebivolol (10.1\% of patients) and simvastatine (6.7\% of patients) are the drugs the most often prescribed (Table 4).

(d) At least one medication with no specific recommendation of dose modification based on $\mathrm{CrCl}$ was prescribed to $62.6 \%$ of all patients $(8.27 \%$ of the drugs prescribed); Bisoprolol (16.7\% of patients, clopidogrel (16.4\% of patients) and fluindione (12.9\% of patients) are the drugs the most often prescribed (Table 4).

Renal misprescribing affected the $39.5 \%$ of patients who had at least one medication prescribed at an inappropriate dose. The medications with the most frequently inappropriate doses were allopurinol $(60.7 \%$ of patients), atenolol (40.8\%), digoxin (57.1\%), ofloxacin (33.3\%), betaxolol (75\%), amoxicillin/clavulanate (100\%), ciprofloxacin (33.3\%) and sulfamethoxazole/trimethoprime (33.3\%) (Fig. 2).

At least 1 PIM was prescribed to $57.6 \%$ of all patients (Fig. 1). Most PIM were antihypertensive drugs (36\% of 


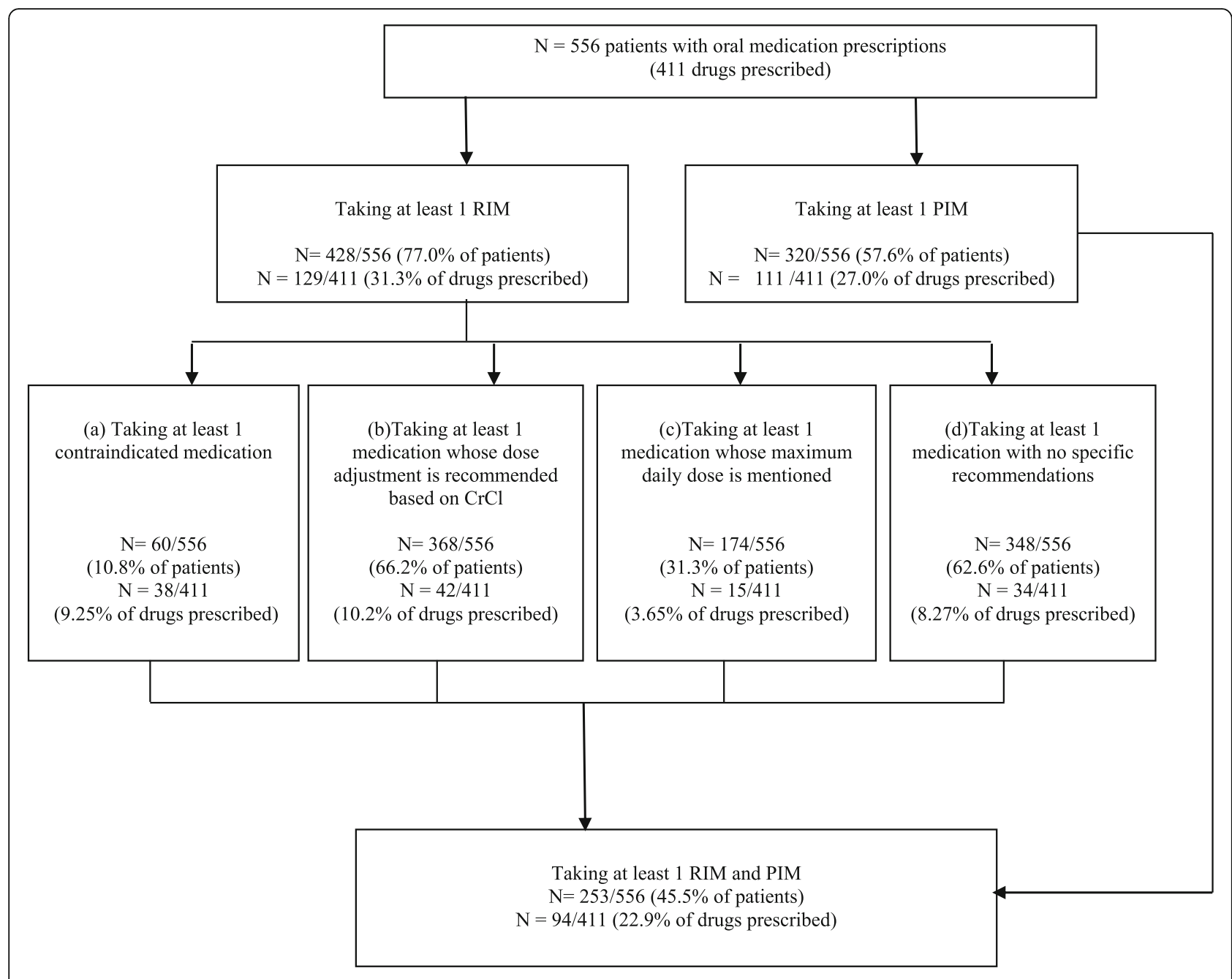

Fig. 1 Use of medications classified as renally inappropriate medications (RIMs) and potentially inappropriate-for-the-elderly medications (PIMs)

Table 3 Contraindicated medications prescribed most frequently for the study population, defined by the CG equation

\begin{tabular}{ll}
\hline Medications & Patients (\%) \\
\hline Rilmenidine $^{a}$ & $92(16.5)$ \\
Rosuvastatin & $36(6.5)$ \\
Alfuzosin $_{\text {Buflomedil }^{\text {a }}}$ & $32(5.8)$ \\
Acarbose $_{\text {Citalopram }}$ & $20(3.6)$ \\
Fenofibrate & $9(1.6)$ \\
Indapamide & $9(1.6)$ \\
Spironolactone & $9(1.6)$ \\
Colchicine, tiemonium, opium & $9(1.6)$ \\
\hline
\end{tabular}

aimenidine and buflomedil are both Renally Inappropriate Medications (RIM) and Potentially Inappropriate-for-the-elderly Medication (PIM) patients) and sedative or hypnotic drugs (20\% of patients). At least 1 medication that is both RIM and PIM was prescribed to $45.5 \%$ of all patients. Lorazepam, hydroxyzine, and rilmenidine were the most prescribed PIM that are simultaneously RIM (Table 5). Patient characteristics associated with RIM and PIM in the multivariate analysis are presented in supplementary data (See additional files 2 and 3). RIM is associated with lower BMI, independent living (in the community), lower eGFR, and PIM with higher systolic blood pressure and lower dysrhythmia.

\section{Discussion}

We report a complex medical regimen with polypharmacy averagingo9 [7-11] medications prescribed for daily administration in this population $\geq 75$ year with advanced CKD and comorbid conditions. Antihypertensive treatment, antithrombotics, and antianemics were the major classes of medication prescribed. Moreover, 77\% of these patients with advanced CKD had at least 1 
Table 4 Most common mmedications requiring dose adjustment or precautions, defined by the CG equation

\begin{tabular}{|c|c|c|}
\hline Category & Medications & $\begin{array}{l}\text { Patients } \\
\text { (\%) }\end{array}$ \\
\hline \multirow{8}{*}{$\begin{array}{l}\text { dose modification is recommended based on } \\
\mathrm{ClCr}\end{array}$} & Allopurinol & $167(30)$ \\
\hline & Atenolol & $34(6.1)$ \\
\hline & Acebutolol & $31(5.6)$ \\
\hline & Lorazepam $^{a}$ & $31(5.6)$ \\
\hline & Hydroxyzine $e^{a}$ & $27(4.9)$ \\
\hline & Perindopril & $20(3.6)$ \\
\hline & Bromazepam $^{\mathrm{a}}$ & $17(3.1)$ \\
\hline & Tianeptine & $15(2.7)$ \\
\hline \multirow{3}{*}{$\begin{array}{l}\text { dose modification based on } \mathrm{CrCl} \text { is not } \\
\text { recommanded but a maximum daily dose is } \\
\text { mentionned }\end{array}$} & Ramipril & 70 (12.6) \\
\hline & Nebivolol & $56(10.1)$ \\
\hline & Simvastatin & $37(6.7)$ \\
\hline \multirow[t]{9}{*}{ no specific recommendations } & Bisoprolol & $93(16.7)$ \\
\hline & Clopidogrel & $91(16.4)$ \\
\hline & Fluindione & $72(12.9)$ \\
\hline & Pravastatin & $53(9.5)$ \\
\hline & Repaglinide & $35(6.1)$ \\
\hline & Candesartan & $31(5.6)$ \\
\hline & Warfarin & $15(2.7)$ \\
\hline & Clonazepam & $14(2.5)$ \\
\hline & Celiprolol & $14(2.5)$ \\
\hline
\end{tabular}

$\mathrm{CrCl}$ Creatinine clearance

a Lorazepam, Hydroxyzine and Bromazepam are both Renally Inappropriate

Medications (RIM) and Potentially Inappropriate-for-the-elderly Medication (PIM)

medication prescribed that is either contraindicated or requires dose adjustments/precautions due to advanced CKD; $57.6 \%$ of patients had at least 1 PIM and $45.5 \%$ has at least one medication that is both RIM and PIM. Renal misprescribing was demonstrated by the $39.5 \%$ of patients with at least one medication prescribed at an inappropriate dose. Deprescription is especially important for central antihypertensive drugs, long-term benzodiazepines, and anticholinergic drugs such as hydroxyzine in this population because of the risk of ADR.

We observed more polymedication than Breton et al. [1] who reported an average of $7.1 \pm 2.7$ medications per day for patients in France with eGFR $<30$ $\mathrm{ml} / \mathrm{min} / 1.73 \mathrm{~m} 2$ and a mean age of 74.3 years \pm 5.4 ; they included, however, few patients with eGFR $<30$ $\mathrm{ml} / \mathrm{min} / 1.73 \mathrm{~m} 2$. Other studies have showed that patients with stage 3-5 CKD have 6 to 8 medications per day, while patients with CKD stage 5 treated with dialysis take a median of 12 per day $[2,6]$. These studies, however, were conducted in the USA where the national insurance system differs from the French public healthcare system; in the United States of America, insurance companies must approve drug prescriptions, which probably reduces the number taken.

As expected in our population, most medication prescriptions concerned the cardiovascular system and especially antihypertensive treatment due to the high prevalence of hypertension in this population [19]. The prevalence of antihypertensive drugs in our study is 10 to $50 \%$ higher than that previously reported among elderly people without advanced CKD and with good blood pressure control $[10,20]$. Strict control of blood pressure is recommended for all patients with CKD, according to the latest European Society of Hypertension (ESH) Guidelines [21]. ACEi and ARB medication, that is, RASi, accounted for $47 \%$ of the antihypertensive treatment in our study, a level similar to other published results $[4,22]$. Other studies have reported a higher level of RASi prescription with the same proportion of diabetic patients, but for younger patients and those with less severe CKD [23, 24]. These ESH therapy guidelines recommend RASi because of their potential to lower blood pressure and reduce albuminuria, as well as their potential benefits in patients with CHF [25]. Yet even in the absence of albuminuria, RASi are recommended to reduce the risk of cardiovascular events [26]. Unsurprisingly, in our population with advanced CKD and diabetes or CHF, the rate of RASi prescription was only around $50 \%$, as these medications are often avoided because of the potential risk of hyperkalemia and acute kidney injury (AKI). With advanced CKD, the benefit of stopping RASi for delaying renal replacement therapy is currently being evaluated in an ongoing interventional study [27].

Patients in our study took numerous medications for metabolic complications, such as drugs to treat hyperphosphatemia and hyperkaliemia, lipid-modifying agents, and vitamins. In later stages of CKD, patients develop numerous metabolic complications that require the prescription of multiple drugs that must comply with guidelines [28]. More surprising is the high rate of pump proton inhibitor (PPI) prescription in our study. Patients with oral anti-thrombotics had a higher frequency of PPI prescription (152/340 (45\%) versus 66/216 (30\%)). PPIs may be dangerous when used long-term in elderly patients with CKD because of malabsorption of vitamins (B12, iron, calcium, and magnesium, with the associated risks of fractures, enteral infections, and AKI) [29]. Recent studies show that PPI use is associated with a higher risk of CKD, CKD progression, and end stage of renal disease, probably because of repeated, unrecognized AKI and hypomagnesemia [30]. Indications for PPI, especially long-term treatments, must be reassessed for patients with CKD, and preference given to safer alternative, such as antihistaminic $\mathrm{H} 2$. 


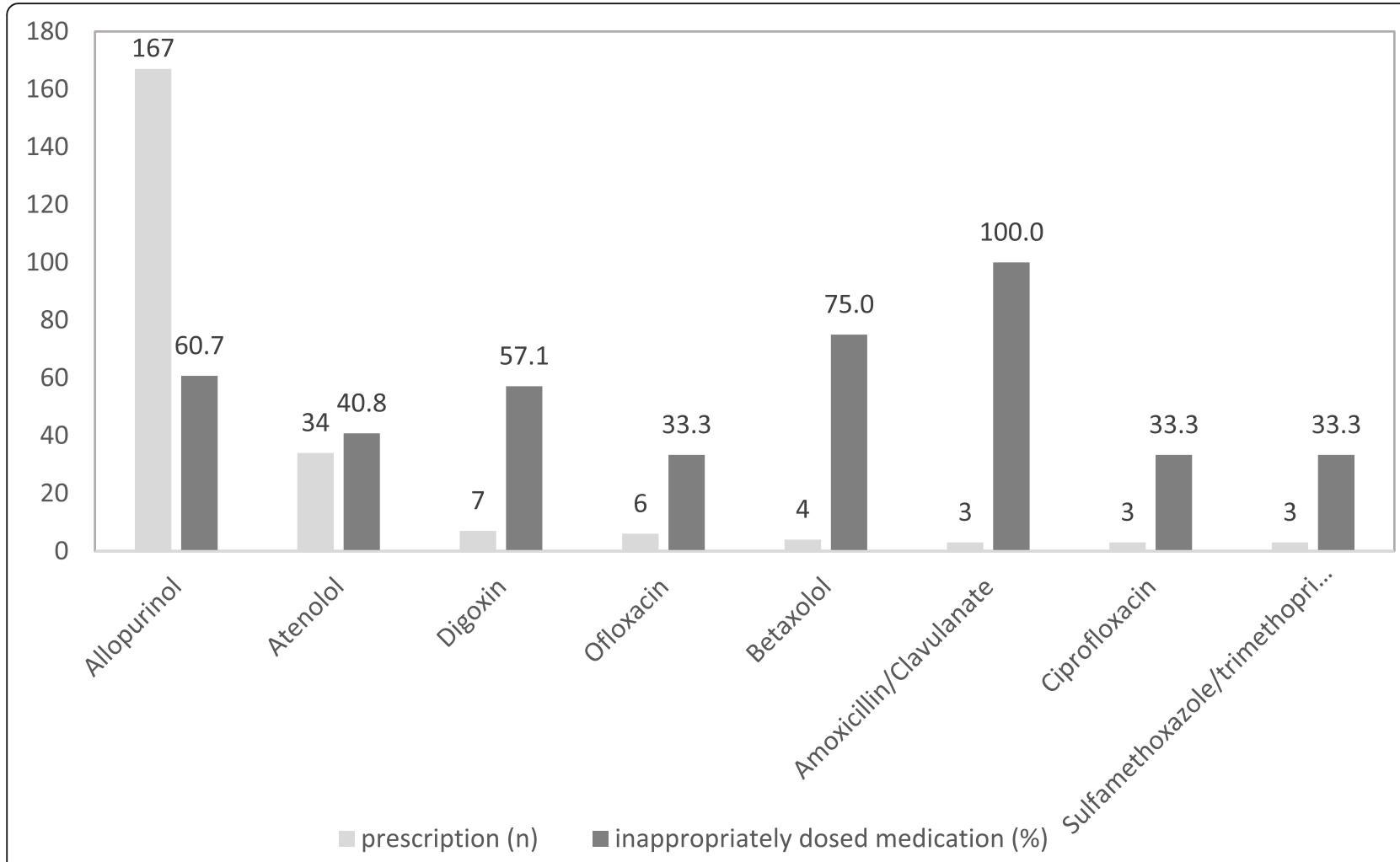

Fig. 2 Most frequently medications prescribed at an inappropriate dose for patients with severe chronic kidney disease

The prevalence of RIM prescriptions in our study (77\%) is higher than the prevalence reported in the recent american study by Chang et al. [6], studying patients with CKD stages 3-5. Because of their possible side effects, RIM must usually be reassessed frequently, especially as eGFR worsens; safer alternatives must be chosen if possible, especially for those RIM that are contraindicated. Despite contraindications, some drugs continue to be prescribed, either because of positive benefit/ risk ratio or post-marketing studies have demonstrated safety, nor when no alternative exists. For example, rilmenidine could be used at a dose of $1 \mathrm{mg}$ but only if hypertension is uncontrolled with optimum doses of diuretics, ARBs and ACEi, beta blockers, and calcium channel blockers, in combination [31]. However, urapidil, which is a drug that is belonging to the same class of hypertensive agents, is not contraindicated and requires no dose adjustment. Rosuvastatin is the second most contraindicated drug prescribed in our study. The specific hepatic metabolism of this drug means that its plasma concentration is 3 times higher in these patients than in individuals without CKD [32]. An initial $5 \mathrm{mg}$ dose of rosuvastatin with a maximum of $10 \mathrm{mg}$ appears useful, but atorvastatin is a safe alternative [33, 34]. A post-marketing study showed that the use of alfusozin and citalopram appears safe $[35,36]$. When no alternatives exist (colchicine for the treatment of acute gout, spironolactone for heart failure), the dose must be as low as possible and reassessed. The other contraindicated drugs used in our study (buflomedil, acarbose, fenofibrate, indapamide) concerned only $9 \%$ of our elderly patients and must be reassessed. Allopurinol is the most frequently prescribed medication that requires dose adjustment: it was given at inappropriate doses to two thirds of the patients taking. Medication prescription of allopurinol requires dose adjustment in view of the toxicity of allopurinol in patients with CKD, including rash, gastrointestinal intolerance, leukopenia, and severe hypersensitivity reaction [37]. However, decreasing uric acid levels in hyperuricemic patients with CKD to slow CKD progression is still controversial [37].

It is essential to select the safest drug or to adapt the dosage in order to prevent drug related problem. But little information is available on the aging-related changes and CKD-related changes in pharmakocinetic and pharmacoynamic profile of a number of drugs. In our study, we found that for $8.27 \%$ of prescribed drugs (that concerned $62.6 \%$ of patients), there is no specific recommendations of dose adjustment. Moreover renal misprescribing affected $39.5 \%$ of patients who had at least one medication prescribed at an inappropriate dose. It is important to ensure appropriate doses are prescribed in relation to the level of renal impairment. Therapeutic monitoring is possible for some drugs (for 
Table 5 Common potentially inappropriate medications with renal contraindications, dose adjustments, or precautions for the study population

\begin{tabular}{|c|c|c|c|}
\hline Medications that are both PIM and RIM & Group of drug & $\mathrm{DCl}$ & Patients n (\%) \\
\hline & Central hypertensive drug & Rilmenidine & $92(16.5)$ \\
\hline & Central hypertensive drug & Moxonidine & $9(1.6)$ \\
\hline & Central hypertensive drug & Clonidine & $6(1.1)$ \\
\hline & Central hypertensive drug & Methyldopa & $1(0.2)$ \\
\hline & Long-term benzodiazepine & Lorazepam & $31(5,6)$ \\
\hline & Long-term benzodiazepine & Bromazepam & $17(3.1)$ \\
\hline & Long-term benzodiazepine & Clonazepam & $14(2.5)$ \\
\hline & Long-term benzodiazepine & Clorazepate & $8(1.4)$ \\
\hline & Long-term benzodiazepine & Lormetazepam & $6(1.1)$ \\
\hline & Long-term benzodiazepine & Clobazam & $5(0.9)$ \\
\hline & Long-term benzodiazepine & Prazepam & $3(0.5)$ \\
\hline & Long-term benzodiazepine & Clotiazepam & $2(0.4)$ \\
\hline & Long-term benzodiazepine & Loprazolam & $2(0.4)$ \\
\hline & Long-term benzodiazepine & Ethylloflazepate & $1(0.2)$ \\
\hline & Anticholinergic drug & Hydroxyzine & $27(4.9)$ \\
\hline & Anticholinergic drug & Mirtazapine & $9(1.6)$ \\
\hline & Anticholinergic drug & Amitriptyline & $4(0.7)$ \\
\hline & Anticholinergic drug & Dexchlorpheniramine & $3(0.5)$ \\
\hline & Anticholinergic drug & Alimemazine & $2(0.4)$ \\
\hline & Anticholinergic drug & Ropinirole & $1(0.2)$ \\
\hline & Vasodilator & Buflomedil & $20(3.6)$ \\
\hline & Vasodilator & Pentoxifylline & $3(0.5)$ \\
\hline & Other & Digoxin & $10(1.8)$ \\
\hline & Other & Opium+Cafeine+paracetamol & $5(0.9)$ \\
\hline & Other & Baclofen & $1(0.2)$ \\
\hline & Other & Nitrofurantoin & $1(0.2)$ \\
\hline
\end{tabular}

exemple fluindione) but it is not available for all medications. Providers reported poor knowledge of medications requiring dosage adjustment; health information technologies, with computerized alerts could be helpful guide for physician prescribing practice in patient with CKD [38]. But collaborative strategies, such as the routine inclusion of pharmacists in the CKD care model shown more effectiveness [39]. Moreover there is a lack of evidence-based data to guide physicians on precautions and dosage adjustments and a lack of quantitative recommendations in the informations sources [40]. The safety profile of some drugs in case of renal impairment is often based upon knowledge of postmarketing rather than controlled trial. For exemple, for cardiovascular drugs, the information sources often did not provide explicit information for dosage adjustment [41]. Instead of a clear quantitative recommendation, terms like "reduce the dose" or "loading dose should be conservative" were often use. In these cases, we only can recommend some measures to reduce the risk of adverse events: (a) the initiation dose of drugs that require dose adjustment or precautions must be as low as possible, (b) the strategy "start low, go slow" must be preferred, (c) the benefit/ risk ratio of each medication must be checked and medication management therapy should regularly be review.

The prevalence of PIM observed in our study is lower than that reported in the USA study by Jones et al. [10], which included 100 patients with CKD stages 3-5 and a mean age of 80 years; instead it is very similar to that reported in other studies focused on elderly patients but without advanced CKD [7, 42]. Pharmacological treatment for elevated blood pressure in advanced CKD patients often requires a combination of several antihypertensive medications, such as central hypertensive drugs, to reach blood pressure (BP) goals [43]. Rilmenidine is often prescribed, but is not recommended to control BP in the elderly or in CKD patients [31]. Other antihypertensive medications should be 
optimized. Other PIM, such as long-term benzodiazepines, cerebral and peripheral vasodilators, and anticholinergic drugs, are widely prescribed in the elderly without advanced CKD, despite the risks of falls and sedation, particularly in France [7]. Anticholinergic drugs are mainly $\mathrm{H} 1$-antihistamines and neuroleptics. H1-Antihistamines are frequently used to treat uremic pruritus but these drugs showed less effectiveness to treat uremic pruritus than gabapentin [44]. Neuroleptics (i.e mirtazapine and alimemazine) are often used for their hypnotic properties instead of more appropriate hypnotic drugs like short- acting benzodiazepines.

Discontinuation of or substitution for drugs that are PIM and RIM in elderly patients with advanced CKD must be considered [45]. Finally, special attention should be paid to patients with higher systolic blood pressure (BP), body mass index (BMI), lower CG-defined GFR, and living independently, as these groups are associated with higher risks of treatment by PIMs or RIMs. There are alternatives to the beer's criteria or the French list of Laroche such as the STOPP (Screening Tool of Older Person's potentially Inappropriate Prescriptions) and START (Screening Tool to Alert Doctors to Right Treatment) criteria. These criteria allowed to detect not only misuse but underuse too. Some studies have demonstrated a very low prescription rate of targeted medications within specific CKD patient [23]: for exemple RASi for patients with diabetes and proteinuria, iron and erythropoietin for anaemic patients, statin for patients with coronary artery disease. Our study doesn't detect this underuse, probably because our patients had at least one consultation with a nephrologist. To our knowledge, there is no specific tool for CKD patients to detect misuse and underuse medications.

Our study has various limitations that should be addressed. First, it may paint an overly rosy picture of overall prescriptions, as all these patients were included in the study by nephrologists, who should already have detected and rectified use of medications that are contraindicated or require dose adjustments. Prescription information was recorded by the nephrologist from the patient's prescriptions; it is therefore possible that prescriptions by other doctors (for example general practitioners) or self-medication were missed. Use of self medication is current in the Elderly [3]. For example, Nonsteroidal antinflammatory drugs are widely available over the counter and patients use them on their own without advertising their healthcare providers [46]. No medication history was performed during the study. However, medication history should be obtain by the intervention of a clinical pharmacist. It must gather at least 3 sources of information that could be patient's interview, phone contact with the community pharmacist and/or the general practitioner, review of self- prepared, medication list or personal medical records, review of medication containers, summaries of previous hospitalization or outpatient visits, in order to obtain the mot possible accurate updated list of current medication. In our study daily medication burden were thus probably underestimated. Moreover, because most of the patients included in the study were living independently in the community, these results are difficult to generalize to institutionalized elderly patients. Second, no information is available about medication adherence or about possible ADRs or other events that might have influenced the observed prescriptions. Third, we did not evaluate the risk of ADR associated with medication interactions. The follow-up of the cohort presumably could look at ADRs. Fourth, the generalizability of the results will be restricted to CKD French clinic and need to be validated in non CKD clinic and other health care systems. Finally, we used 2015 recommendations for the qualitative evaluation of medications [47], although our prescriptions come from 2010, and we have no information about practitioners' changes in prescription practices since then. The follow-up of the cohort presumably could look at ADRs. Otherwise statistical approach used to identify patient's characteristics associated to PIM and RIM prescription could result in overfitting limiting generalizability of these results. The major strength of this study is the large elderly population with advanced CKD from more than 20 nephrology departments under the care of 70 nephrologists in France, which provides a description of the overall and relatively unknown medication patterns in this particular population.

Our study showed that reassessment of medication prescriptions is needed for elderly patients with advanced CKD. Collaboration and good communication between general practitioners, nephrologists, cardiologists, pharmacists, and geriatricians is required to review the appropriateness of medication prescription [2]. Heath professionals must develop an effective partnership with the patients. Medication review, medication reconciliation, patient counseling, and multidisciplinary meetings are several important approaches to improving medication safety [48] by conducting a benefit-risk analysis for indications, dosage, interactions, side effects, adherence to guidelines for elderly patients and those with advanced CKD. At the end of this medication review, physicians should limit the number of medications as far as possible, but the development of an algorithm ensuring that the highest priority drugs are prescribed in this population is essential. Limiting the number of medications should also improve patient adherence but deprescribing is a real challenge $[49,50]$. After this showing of the exposure of elderly people with advanced CKD to both RIM and PIM, further studies must examine the impact of deprescription of these targeted medications. 


\section{Conclusion}

In this study, we reported polypharmacy and exposure to potential drug-related problems in elderly patients with advanced CKD. In this population, healthcare providers must be more aware of the need to evaluate the benefit-risk ratio of each medication prescribed, such as the specific medications identified in this study. Collaborative patient-centered approaches with all patients' health care professionals must be developed. Finally, the development of new medication needs to consider this complex polypharmacy in this growing population.

\section{Supplementary information}

Supplementary information accompanies this paper at https://doi.org/10 1186/s12877-020-1485-4.

Additional file 1. Characteristics of patients with prescriptions for $\mathrm{ARBs}^{*}$ or ACE inhibitors** (* ARB: Angiotensin receptor blocker, ${ }^{* *} \mathrm{ACEi}$ Angiotensin-converting enzyme inhibitor)

Additional file 2. Characteristics of patients according to the Renally Inappropriate Medication (RIM) according to Cockroft Gault formula prescription

Additional file 3. Characteristics of patients according to Potentially Inappropriate Medications (PIM) prescription

\section{Abbreviations}

ACEi: Angiotensin Converting Enzym Inhibitor; ADR: Adverse Drug Reaction; AKl: Acute Kidney Injury; ARB: Angiotensin Receptor Blocker; ATC: Anatomical Therapeutic Chemical classification; BMI: Body Mass Index; BP: Blood Pressure; BSA: Body Surface Area; CCTIRS: Comité Consultatif sur le Traitement de I'Information en Recherche en Santé (French: Consultative Committee on the Treatment of Information on Personal Health Data for Research Purposes); CG: Cockcroft and Gault; CHF: Chronic Heat Failure; CKD: Chronic Kidney Disease; CNIL: Commission Nationale de I'Informatique et des Libertés (French: National Data Protection Authority); eGFR: estimated Glomerular Filtration Rate; EMA: European Medicine Agency; ESH: European Society of Hypertension; FDA: Food And Drug Agency; GFR: Glomerular Filtration Rate; KDIGO: Kidney Disease Improving Global Outcomes; MDRD: Modification Of Diet in Renal Disease; PIM: Potentially Inapropriate Medication; PPI: Pump Proton Inhibitor; PSPA: Parcours de Soin Personnes Agées (French: Care Pathway of the Elderly); RASi: Renin Angiotensin System inhibitors; RIM: Renally Inapropriate Medication; SD: Standard Deviation; SRAi: System Renin Angiotensin Inhibitors; WHO: World Health Organization

\section{Acknowledgments}

French centers that participated in the study (heads of departments, investigators):

Y Lemeur (Chu Brest), T Lobbedez (CHU Caen), C Passeron (CH Cannes), A Djema (CH Cholet), M Matignon (APHP, Creteil), P Zaoui (CHU Grenoble), I Farah (CH Le mans), E Boulanger (CHU Lille), V Allot (CHU Limoges), S Roche (CH Macon), J Sampol (Clinique Bouchard, Marseille), D Babici (CH Mulhouse), O Moranne (CHU Nice), M Souid (CH Poissy), F Bridoux (CHU Poitiers), C Vigneau (CHU Rennes), J Potier (CH St Brieuc), C Mariat (CHU St Etienne), E Renaudineau (CH Saint Malo), S Roueff (CH Saint Maurice), A Kolko-Labadens (Hopital Foch), M Francois (CHU Tours), L Vrigneaud, D Fleury (CH Valenciennes), Didier Aguiléra (CH Vichy).

The authors thank the University Hospital of Nîmes for its structural, human and financial support through the award obtained by our team during the internal call for tenders "Thématiques émergentes."

The authors also thank Jo Ann Cahn for reviewing the English.

\section{Authors' contributions}

$\mathrm{OM}, \mathrm{CV}$ et CC designed the study. CF conducted the statistical analyses. CRM, JBB, GE and OM conducted data analysis. CRM and OM performed data interpretation, and drafted of the manuscript. All authors contributed to the interpretation of the data, and results, revisions, and approved the final version of the manuscript.

\section{Funding}

Financial support for the PSPA project including disclosure of financial interests: Agence de Biomedecine (Grant 2009 \& 2012), Société Francophone de Néphrologie et de Dialyse (Grant 2014) and Roche, Baxter, Amgen, Fresenius.

The funders played no role in the study design, data collection and analysis, decision to publish, or preparation of the manuscript.

\section{Availability of data and materials}

The datasets used and/or analyzed during the current study are available from the corresponding author

\section{Ethics approval and consent to participate}

The Institutional Review Board and Ethics Committee of the research institution (Nîmes University Hospital Center), as well as two national bodies, the National Data Protection Authority (CNIL) and the Consultative Committee on the Treatment of Information on Personal Health Data for Research Purposes (CCTIRS), approved the study and the method of consent. The study was registered as clinical trial number NCT02910908. All patients provided written consent to participate.

\section{Consent for publication}

Not applicable.

\section{Competing interests}

Authors have no competing interest to report as described by BMC Geriatrics.

\section{Author details}

'Department of Pharmacy, Nîmes University Hospital, Nîmes, France. ${ }^{2}$ Laboratoire Epidemiologie, Santé Publique, Biostatistiques, Université Montpellier, EA2415 Nimes, France. ${ }^{3}$ Department of Nephrology, Dialysis and Apheresis, Nîmes University Hospital, Nîmes, France. ${ }^{4}$ Nice, France. ${ }^{5} \mathrm{CHU}$ Rennes, Department of nephrology, 3 rue H le Guilloux, 35000 Rennes, France. ${ }^{6}$ INSERM U1085-IRSET, Rennes, France. ${ }^{7}$ REIN registry, Agence de la biomédecine, 1 avenue du stade de France, 93212 Saint Denis La Plaine, Saint-Denis, France. ${ }^{8}$ Laboratoire Biostatistique Santé Université Claude Bernard Lyon I, UMR CNRS 5558, Lyon, France.

Received: 31 May 2019 Accepted: 20 February 2020

Published online: 04 March 2020

\section{References}

1. Breton G, Froissart M, Janus N, Launay-Vacher V, Berr C, Tzourio C, et al. Inappropriate drug use and mortality in community-dwelling elderly with impaired kidney function--the Three-City population-based study. Nephrol Dial Transplant. 2011;26(9):2852-9.

2. Cardone KE, Bacchus S, Assimon MM, Pai AB, Manley HJ. Medication-related problems in CKD. Adv Chronic Kidney Dis. 2010;17(5):404-12.

3. Qato D, Caleb G, Johnson M, Schumm P, Tessler LS. Use of prescription and over-the-counter medications and dietary supplements among older adults in the United States. JAMA. 2008;300(24):2867.

4. Hsu KL, Fink JC, Ginsberg JS, Yoffe M, Zhan M, Fink W, et al. Self-reported medication adherence and adverse patient safety events in CKD. Am J Kidney Dis. 2015:66(4):621-9.

5. Wong NA, Jones HW. An analysis of discharge drug prescribing amongst elderly patients with renal impairment. Postgrad Med J. 1998;74(873):420-2.

6. Chang F, O'Hare AM, Miao Y, Steinman MA. Use of Renally inappropriate medications in older veterans: a National Study. J Am Geriatr Soc. 2015; 63(11):2290-7.

7. Bongue B, Laroche ML, Gutton S, Colvez A, Guéguen R, Moulin JJ, et al. Potentially inappropriate drug prescription in the elderly in France: a population-based study from the French National Insurance Healthcare system. Eur J Clin Pharmacol. 2011;67(12):1291-9.

8. By the American Geriatrics Society 2015 Beers Criteria Update Expert Panel. American Geriatrics Society 2015 Updated Beers Criteria for Potentially Inappropriate Medication Use in Older Adults. J Am Geriatr Soc. 2015;63(11):2227-46. 
9. Laroche M, Charmes J, Nouaille Y, Fourrier A, Merle L. Impact of hospitalisation in an acute medical geriatric unit on potentially inappropriate medication use. Drugs Aging. 2006;23(1):49-59.

10. Jones SA, Bhandari S. The prevalence of potentially inappropriate medication prescribing in elderly patients with chronic kidney disease. Postgrad Med J. 2013;89(1051):247-50.

11. Fick DM, Waller $J \mathrm{~L}$, Maclean JR. Potentially inappropriate medication use in a Medicare managed care population: association with higher costs and utilization. J Manag Care Pharm. 2001;7(5):407-13.

12. Quintana-Bárcena P, Lord A, Lizotte A, Berbiche D, Lalonde L. Prevalence and management of drug-related problems in chronic kidney disease patients by severity level: a subanalysis of a cluster randomized controlled trial in community pharmacies. J Manag Care Spec Pharm. 2018;24(2):173-81.

13. Moranne O, Couchoud C, Vigneau C. PSPA study investigators. Characteristics and treatment course of patients older than 75 years, reaching end-stage renal failure in France. The PSPA study. J Gerontol A Biol Sci Med Sci. 2012;67(12):1394-9.

14. WHO Collaborating Centre for Drug Statistics Methodology, ATC/ DDD Index 2009. http://www.whocc.no/atcddd/. Accessed 20 Feb 2020.

15. Information Conseil Adaptation Rénale ICAR. http://www.sitegpr.com/. Accessed 20 Feb 2020

16. EMA. Guideline on the evaluation of the pharmacokinetics of 4 medicinal products in patients with decreased renal 5 function. Available at hhttp:// www.ema.europa.eu/docs/en_GB/document_library/Scientific_guideline/2 016/02/WC500200841.pdf. Accessed 20 Feb 2020.

17. FDA. Pharmacokinetics in patients with impaired renal function -study design, data analysis, and impact on dosing and labeling. Available at https://www.fda. gov/downloads/Drugs/GuidanceComplianceRegulatorylnformation/ Guidances/UCM072127.pdf. Accessed 20 Feb 2020.

18. Laroche M-L, Bouthier F, Merle L, Charmes J-P. Potentially inappropriate medications in the elderly: interest of a list adapted to the French medical practice. Rev Med Interne. 2009;30(7):592-601.

19. Gargiulo R, Suhail F, Lerma EV. Cardiovascular disease and chronic kidney disease. Dis Mon. 2015;61(9):403-13.

20. Laroche M-L, Charmes J-P, Nouaille Y, Picard N, Merle L. Is inappropriate medication use a major cause of adverse drug reactions in the elderly? $\mathrm{Br} J$ Clin Pharmacol. 2007;63(2):177-86.

21. Mancia G, Fagard R, Narkiewicz K, Redán J, Zanchetti A, Böhm M, et al. 2013 practice guidelines for the management of arterial hypertension of the European Society of Hypertension (ESH) and the European Society of Cardiology (ESC): ESH/ESC task force for the Management of Arterial Hypertension. J Hypertens. 2013;31(10):1925-38.

22. Nissenson AR, Collins AJ, Hurley J, Petersen H, Pereira BJ, Steinberg EP. Opportunities for improving the care of patients with chronic renal insufficiency: current practice patterns. J Am Soc Nephrol. 2001;12(8):1713-20.

23. Bailie GR, Eisele G, Liu L, Roys E, Kiser M, Finkelstein F, et al. Patterns of medication use in the RRI-CKD study: focus on medications with cardiovascular effects. Nephrol Dial Transplant. 2005;20(6):1110-5.

24. Tonelli M, Bohm C, Pandeya S, Gill J, Levin A, Kiberd BA. Cardiac risk factors and the use of cardioprotective medications in patients with chronic renal insufficiency. Am J Kidney Dis. 2001;37(3):484-9.

25. Ponikowski P, Voors AA, Anker SD, Bueno H, Cleland JGF, Coats AJS, et al. 2016 ESC guidelines for the diagnosis and treatment of acute and chronic heart failure: the task force for the diagnosis and treatment of acute and chronic heart failure of the European Society of Cardiology (ESC). Developed with the spec. Eur J Heart Fail. 2016;18(8):891-975.

26. Ruilope LM. Chronic kidney disease: blood pressure control in CKD--still a matter of debate. Nat Rev Nephrol. 2013;9(10):572-3.

27. Ahmed AK, Kamath NS, El Kossi M, El Nahas AM. The impact of stopping inhibitors of the renin-angiotensin system in patients with advanced chronic kidney disease. Nephrol Dial Transplant. 2010;25(12):3977-82.

28. Moranne O, Froissart M, Rossert J, Gauci C, Boffa J-J, Haymann JP, et al. Timing of onset of CKD-related metabolic complications. J Am Soc Nephrol. 2009;20(1):164-71.

29. Ito T, Jensen RT. Association of Long-Term Proton Pump Inhibitor Therapy with bone fractures and effects on absorption of calcium, vitamin B12, Iron, and magnesium. Curr Gastroenterol Rep. 2010;12(6):448-57.

30. Sakaguchi Y, Shoji T, Hayashi T, Suzuki A, Shimizu M, Mitsumoto K, et al. Hypomagnesemia in type 2 diabetic nephropathy: a novel predictor of endstage renal disease. Diabetes Care. 2012;35(7):1591-7.
31. Aparicio M, Dratwa M, El Esper N, Fillastre JP, Levaltier B, Lins R, et al. Pharmacokinetics of rilmenidine in patients with chronic renal insufficiency and in hemodialysis patients. Am J Cardiol. 1994;74:43-50.

32. Brown CDA, Windass A, Bleasby $K$, Lauffart B. Rosuvastatin is a high affinity substrate of hepatic organic anion transporter OATP-C. Atheroscler. 2001; 90(supp2): 174

33. Fellström B, Holdaas H, Jardine AG, Rose H, Schmieder R, Wilpshaar W, et al. Effect of Rosuvastatin on outcomes in chronic Haemodialysis patients: baseline data from the AURORA study. Kidney Blood Press Res. 2007;30(5):314-22.

34. Tzeng TB, Schneck DW, Birmingham BK, Mitchell PD, Zhang H, Martin PD, et al. Population pharmacokinetics of rosuvastatin: implications of renal impairment, race, and dyslipidaemia. Curr Med Res Opin. 2008;24(9):2575-85.

35. Marbury TC, Blum RA, Rauch C, Pinquier J-L. Pharmacokinetics and safety of a single Oral dose of once-daily Alfuzosin, $10 \mathrm{mg}$, in male subjects with mild to severe renal impairment. J Clin Pharmacol. 2002;42(12):1311-7.

36. Nagler EV, Webster AC, Vanholder R, Zoccali C. Antidepressants for depression in stage 3-5 chronic kidney disease: a systematic review of pharmacokinetics, efficacy and safety with recommendations by European renal best practice (ERBP)*. Nephrol Dial Transplant. 2012;27(10):3736-45.

37. Kanji T, Gandhi M, Clase CM, Yang R. Urate lowering therapy to improve renal outcomes in patients with chronic kidney disease: systematic review and meta-analysis. BMC Nephrol. 2015; 16(1). Available from: https://doi.org/ 10.1186/s12882-015-0047-z. Cited 2017 Jan 26.

38. Tesfaye WH, Castelino RL, Wimmer BC, Zaidi STR. Inappropriate prescribing in chronic kidney disease: a systematic review of prevalence, associated clinical outcomes and impact of interventions. Int J Clin Pract. 2017;71(7):e12960.

39. Tawadrous D, Shariff S, Haynes R, Lansavichus A, Jain A, Garg A. Use of clinical decision support Systems for Kidney-Related Drug Prescribing: a systematic review. Am J Kidney Dis. 2011;6(58):903-14.

40. Khanal A, Castelino RL, Peterson GM, Jose MD. Dose adjustment guidelines for medications in patients with renal impairment: how consistent are drug information sources?: consistency in renal drug dosing guidelines. Intern Med J. 2014:44(1):77-85.

41. Saheb Sharif-Askari F, Syed Sulaiman SA, Saheb Sharif-Askari N, Al Sayed Hussain A. Development of an Adverse Drug Reaction Risk Assessment Score among Hospitalized Patients with Chronic Kidney Disease. PLoS One. 2014;9(4):e95991 Romagnani P, editor.

42. Gallagher PF, Barry PJ, Ryan C, Hartigan I, O'Mahony D. Inappropriate prescribing in an acutely ill population of elderly patients as determined by beers' criteria. Age Ageing. 2007;37(1):96-101.

43. Ruiz-Hurtado G, Sarafidis P, Fernández-Alfonso MS, Waeber B, Ruilope LM. Global cardiovascular protection in chronic kidney disease. Nat Rev Cardiol. 2016;13(10):603-8.

44. Simonsen E, Komenda P, Lerner B, Askin N, Bohm C, Shaw J, et al. Treatment of uremic pruritus: a systematic review. Am J Kidney Dis. 2017;70(5):638-55.

45. De Rhodes $\mathrm{KH}$. The dangers of ignoring the beers criteria-the prescribing Cascade. JAMA Intern Med. 2019;179(7):863-4.

46. Weir MR, Fink JC. Safety of medical therapy in patients with chronic kidney disease and end-stage renal disease. Curr Opin Nephrol Hypertens. 2014;23(3):306-13.

47. Vidal dictionaries. 91th ed. Vidal Editions Paris: Vidal SA; 2015.

48. Leguelinel-Blache G, Dubois F, Bouvet S, Roux-Marson C, Arnaud F, Castelli

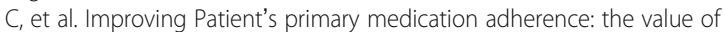
pharmaceutical counseling. Medicine (Baltimore). 2015;94(41):e1805.

49. McIntyre C, McQuillan R, Bell C, Battistella M. Targeted Deprescribing in an Outpatient Hemodialysis Unit: A Quality Improvement Study to Decrease Polypharmacy. Am J Kidney Dis. 2017;S0272-6386(17):30582-6.

50. Triantafylidis LK, Hawley CE, Perry LP, Paik JM. The role of Deprescribing in older adults with chronic kidney disease. Drugs Aging. 2018;35(11):973-84.

\section{Publisher's Note}

Springer Nature remains neutral with regard to jurisdictional claims in published maps and institutional affiliations. 